\title{
Wind Turbine Placement Optimization by means of the Monte Carlo Simulation Method
}

\author{
S. Brusca, ${ }^{1}$ R. Lanzafame, ${ }^{2}$ and M. Messina $^{2}$ \\ ${ }^{1}$ Department of Electronic Engineering, Chemistry and Industrial Engineering, University of Messina, Contrada di Dio, \\ 98166 Messina, Italy \\ ${ }^{2}$ Department of Industrial Engineering, University of Catania, Viale A. Doria 6, 9125 Catania, Italy
}

Correspondence should be addressed to S. Brusca; sbrusca@unime.it

Received 9 January 2014; Accepted 15 May 2014; Published 9 June 2014

Academic Editor: Mohamed B. Trabia

Copyright (c) 2014 S. Brusca et al. This is an open access article distributed under the Creative Commons Attribution License, which permits unrestricted use, distribution, and reproduction in any medium, provided the original work is properly cited.

\begin{abstract}
This paper defines a new procedure for optimising wind farm turbine placement by means of Monte Carlo simulation method. To verify the algorithm's accuracy, an experimental wind farm was tested in a wind tunnel. On the basis of experimental measurements, the error on wind farm power output was less than $4 \%$. The optimization maximises the energy production criterion; wind turbines' ground positions were used as independent variables. Moreover, the mathematical model takes into account annual wind intensities and directions and wind turbine interaction. The optimization of a wind farm on a real site was carried out using measured wind data, dominant wind direction, and intensity data as inputs to run the Monte Carlo simulations. There were 30 turbines in the wind park, each rated at $20 \mathrm{~kW}$. This choice was based on wind farm economics. The site was proportionally divided into 100 square cells, taking into account a minimum windward and crosswind distance between the turbines. The results highlight that the dominant wind intensity factor tends to overestimate the annual energy production by about $8 \%$. Thus, the proposed method leads to a more precise annual energy evaluation and to a more optimal placement of the wind turbines.
\end{abstract}

\section{Introduction}

The current worldwide energy scenario and the stringent regulations on pollutant emissions in the industrialized countries have led to new strategies concerning energy sources and power generation.

The European Parliament has given its backing to the European Union climate change package which ensures that it will achieve its climate targets by 2020 . According to the package, a $20 \%$ reduction in greenhouse gas emissions, a $20 \%$ improvement in energy efficiency, and a $20 \%$ share of renewables in the European Union energy mix should be achieved by 2020 [1].

During 2009, European Union countries installed $10,163 \mathrm{MW}$ of wind power of the 10,526 MW installed across all of Europe [2]. This represents a market growth in the EU of $23 \%$ compared to 2008 installations. Of the $10,163 \mathrm{MW}$ installed in the European Union, 9,581 MW (94.3\%) was onshore, and $582 \mathrm{MW}$ (5.7\%) was offshore. In 2009, the onshore wind power market grew by $21 \%$ compared to the previous year, and the offshore wind power market grew by $56 \%$ compared to the previous year [2].

As far as investment is concerned, during 2009 wind farms amounted to about $€ 13$ billion in the EU. Onshore wind power accounted for $€ 11.5$ billion (88.5\%), and offshore wind power accounted for approximately $€ 1.5$ billion (11.5\%) [3].

Europe's 2009 installations are characterised by continuing strong development in the mature markets of Spain $(2,459 \mathrm{MW})$ and Germany (1,917 MW), together with Italy (1,114 MW), France (1,088 MW), and the United Kingdom (1,077 MW). Portugal (673 MW), Sweden (512 MW), Denmark (334 MW), and Ireland (233 MW) also performed strongly [2].

Wind energy will play an important role in achieving the energy targets. Both small and industrial sized wind turbine systems have the maturity to be considered economically effective. The small wind turbine market is still developing and could see major growth in the near future. 
Taking into account this scenario, it is important to improve energy production from the wind by means of either more efficient wind turbines or enhanced planning of wind farms in terms of wind turbine placement within wind parks and/or location selection. As is obvious, wind turbines are a mature technology and few margins are possible. For highpower wind farms, energy production needs to be optimised to be financially competitive with conventional forms of energy production.

This paper implements a new mathematical optimization procedure for wind turbine positioning within a wind farm. In this study, multicriteria optimization takes into account maximum energy production and minimum cost. The central factors are wind turbine number and their positioning within the farm based on the criteria above. In this study, a new approach was carried out by using the Monte Carlo simulation. Wind turbine interaction and wind speed intensity, as well as wind direction, were taken into account. A MATLAB [3] program code was implemented to run the optimization method. Moreover, this study focused on the Monte Carlo optimization method's effectiveness evaluation to identify the best wind turbine positioning.

\section{Background}

The topic of the best placement of wind turbines has concerned several authors [4-10]. Since the 90s, optimal wind farm turbine positioning has been in rows of $8-12$ rotor diameters apart in the windward direction and 1.5-3 rotor diameters apart in the crosswind direction, as reported in [4] by Patel. As Bansal et al. stated in [5], in that optimal configuration the land requirement for wind farms per installed megawatt is about $10 \mathrm{ha} / \mathrm{MW}$.

As demonstrated by Ammara et al. in [6], Patel's best wind turbine positioning was not exploiting the wind energy potential of the site and therefore Patel's placement was not optimal. As an alternative, Ammara et al. studied a dense, staggered scheme with the same energy production of Patel's, which reduced the land requirement [6]. Yet, this was still an arbitrary method of wind turbine placement.

The problem of designing wind parks has been addressed by Mosetti et al. [7], Kiranoudis et al. [8], Grady et al. [9], and Marmidis et al. [10] with completely different approaches.

In particular, first Mosetti et al. [7] and then Grady et al. [9] used genetic algorithms to determine optimal wind turbine placement in specific wind farms. Mosetti et al.s algorithm evaluated wind farm performance and optimization. The investment cost and total power extracted were used as variables in the optimization procedure. To focus on method feasibility, Mosetti et al. used simple wind (single wind direction and intensity; constant intensity and $360^{\circ}$ variable direction; multiple wind direction and intensity) and cost models. Grady et al. [9] again used genetic algorithms to find the optimal wind turbine configuration in a wind park and, as Mosetti et al., they focused on the effectiveness of the method. Grady et al. studied three different cases again using a simple cost model: uniform wind direction and intensity (12 m/s); multidirectional wind (36 angles from 0-360 deg)

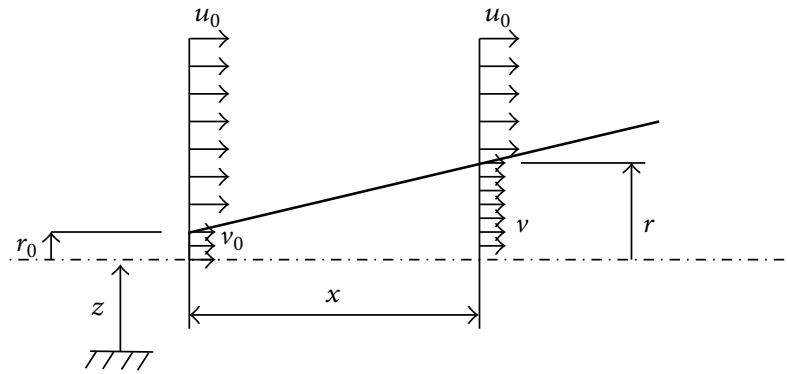

FIgURE 1: Wake scheme.

and mean wind speed (again $12 \mathrm{~m} / \mathrm{s}$ ); multidirectional wind (36 angles from $0-360 \mathrm{deg}$ ) and variable wind speed $(8,12$, and $17 \mathrm{~m} / \mathrm{s}$ ).

Kiranoudis et al. [8] used a different optimization procedure (successive quadratic programming algorithms) accounting for wind turbine type and farm size, as well as the site's wind field characteristics. The number of wind turbines to be installed was evaluated by maximizing the economic benefits of the investment. In Kiranoudis et al. [8], a short-cut empirical equation design was also introduced to determine the optimum number of wind turbines.

Marmidis et al. [10] developed a different methodology based on the same models that Mosetti et al. [7] and Grady et al. [9] used. Marmidis et al's optimization algorithm uses the Monte Carlo simulation method. As reported in [10], the Monte Carlo simulation method manages to better place the wind turbines compared to Mosetti et al. and Grady et al.

\section{Mathematical Model}

In this study, a wake model was implemented according to Jensen [11]. The analysis is based on the assumption that momentum is conserved inside the wake $[12,13]$, neglecting the near field behind the wind generator. The assumption treats the wake behind the wind turbine as a negative jet [14]. Figure 1 shows a wake scheme, where $v_{0}$ is the velocity just behind the rotor, $u_{0}$ is the velocity of the undisturbed wind, and $v$ is the air velocity in the wake at a distance $x$ from the rotor, as well as $r_{0}$, the rotor radius, and $r$, the wake radius at $x$ distance.

For a linear wake it is possible to link the wake radius, the rotor radius, and the distance from the rotor in the wake using the entrainment constant $\alpha$ as reported in

$$
r=r_{0}+\alpha x
$$

The entrainment constant is empirically given by [9]

$$
\alpha=\frac{0.5}{\ln \left(z / z_{0}\right)},
$$

where $z$ is the hub height of the turbine and $z_{0}$ is the ground roughness of the site. 
Moreover, the axial induction factor " $a$ " [15] can be introduced to determine the air velocity just behind the wind turbine rotor (see (3) [9]):

$$
v_{0}=(1-a) u_{0} .
$$

Considering the momentum conservation equation, the wake air velocity can be calculated taking into account (1), (2), and (3) to produce

$$
v=u_{0}\left[1-\frac{a}{\left(1+\alpha\left(x / r_{0}\right)\right)^{2}}\right] .
$$

In the case of a wind turbine running into multiple wakes, a linear composition of the kinetic energy deficits can be assumed. So the kinetic energy of the mixed wake is the sum of constituent wakes' kinetic energy deficits. Consequently, (5) is deduced for the velocity downstream of $N$ turbines [9]

$$
v_{N}=u_{0}\left[1-\sqrt{\sum_{i=1}^{N}\left(1-\frac{v_{i}}{u_{0}}\right)^{2}}\right] .
$$

\section{The Monte Carlo Method}

To analyse systems of large dimensions [14], such as the one in this case, two main methodologies can be used. First, the analytical methodology is based on enumerating the situations that describe components of the whole system. Only critical cases based on study-specific criteria are considered. Second, the statistical methodology is based on the Monte Carlo Simulation Method. This methodology deals with the total number of cases, which is very important in the case of wind turbine placement because every single wind field configuration may be optimal.

The Monte Carlo class of algorithms is based on repeated random sampling to compute the results [16] and tends to be used when it is unfeasible to compute an exact result with a deterministic algorithm. These methods are especially useful for simulating systems with many-coupled degrees of freedom and when phenomena present significant input uncertainty. In the Monte Carlo method, solutions are considered as parameters of a hypothetical population, a sample of which can be constructed using a random sequence of numbers and from which statistical estimates of the parameter can be obtained [17].

\section{Model Validation}

To validate the mathematical model, a small-scale experimental wind farm was built and tested in a wind tunnel $[18,19]$. Five small-scale equally wind turbines were built and their characteristics (Figure 2) were measured using the wind tunnel. These small-scale turbines have a rotor diameter of $80 \mathrm{~mm}$, a hub diameter of $15 \mathrm{~mm}$, and a hub height of $140 \mathrm{~mm}$. Figure 3 shows the small-scale wind turbine's main dimensions.

For the small-scale wind field, a $6 \times 3$ position grid (Figure 4) was built as the bottom surface of the wind-tunnel

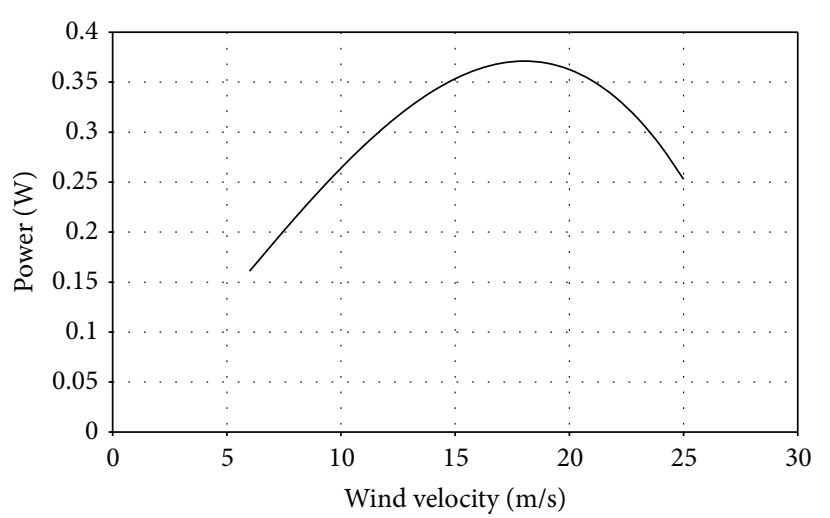

FIGURE 2: Small-scale wind turbine characteristic.

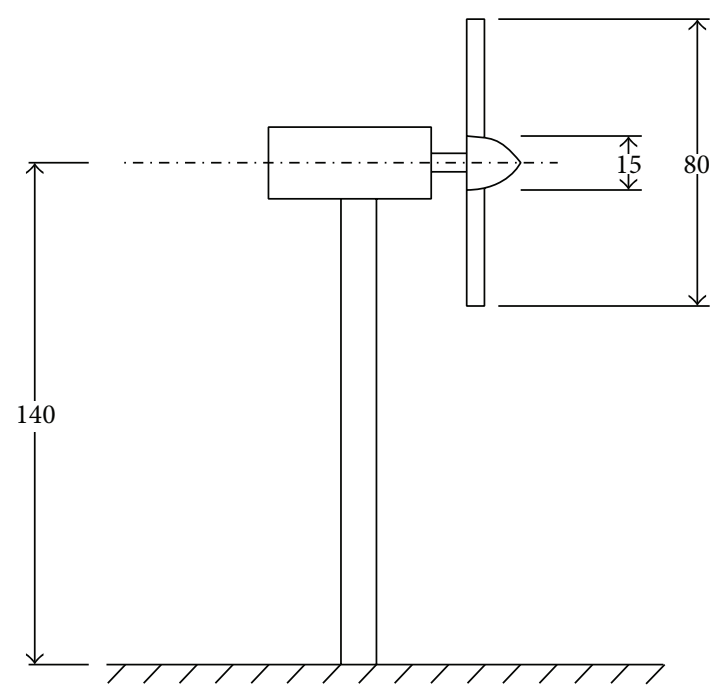

FIGURE 3: Main small-scale wind turbine dimensions.

test section. In this paper, $100 \times 100 \mathrm{~mm}$ cells were used producing a $600 \times 300 \mathrm{~mm}$ grid. Considering the smallscale wind turbine diameter and grid cell dimensions, a 1.25 $d_{0}$ spacing was used. The choice of grid and wind turbine dimensions depended on the maximum size of the wind tunnel test section and minimum wind turbine distances: the minimum distance from the test section inlet $\left(0.3 D_{\mathrm{wt} .}[\mathrm{l}[\mathrm{l}])\right.$ and the minimum distance from the test section outlet $(2 / 3 \mathrm{~L}$ $[18])$. Figure 5 is a photograph of the wind park in the wind tunnel test section.

To validate the mathematical model, experimental tests [19] were carried out on the small-scale wind farm and the results were analysed by analysis of variance [20]. Tests were also conducted in the same configuration applying data from the optimization algorithm (Figure 6). For each small-scale wind turbine, the power generated at constant electric load, wind velocity, and direction $(10 \mathrm{~m} / \mathrm{s}$ and $0 \mathrm{deg})$ was measured. The experimental results were compared to the simulated ones.

Using the optimal placement, a small-scale wind park power of $1.4001 \pm 0.006 \mathrm{~W}$ was measured, while a simulated power of $1.3540 \mathrm{~W}$ was obtained which is a variance of $3.29 \%$. 


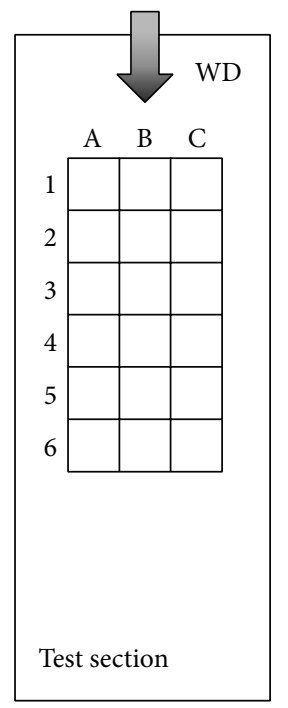

FIGURE 4: Test section: small-scale wind field grid.

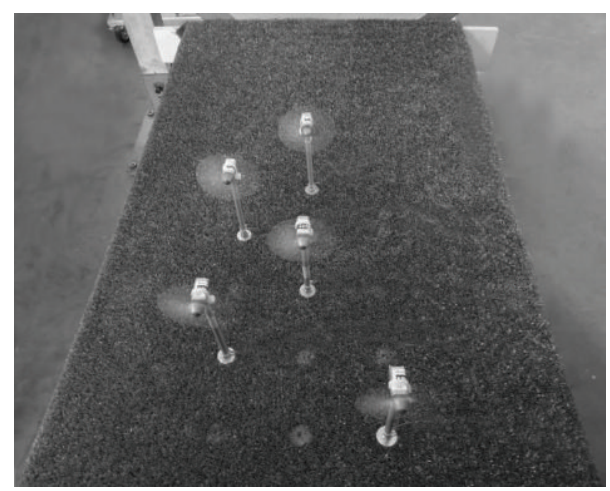

FIGURE 5: Photograph of the wind farm in the wind tunnel test section.

Therefore, the optimization technique may be considered valid.

\section{Case Study}

To simulate the performance of the wind farm, the wind field area was divided into cells in a grid. A wind turbine was placed in the centre of each cell. A square grid was used, which was divided into 100 possible turbine locations [10]. Every cell has a width equal to five rotor diameters, $5 D_{0}[10]$. Thus, the total domain size is $50 D_{0} \times 50 D_{0}$. The rule of thumb spacing requirements [10] in all directions is satisfied by the $5 D_{0}$ square grid size. Furthermore, we applied a coordinate system $(x, y)$ with $x=0, y=0$ in the lower-left corner of the grid so every turbine has positive coordinates $(x>0, y>0)$.

To simulate changing wind direction and wind turbine interactions, the following criteria were considered. For each turbine, a relative coordinates system was defined with the $X$-axis in the opposite direction of the wind direction

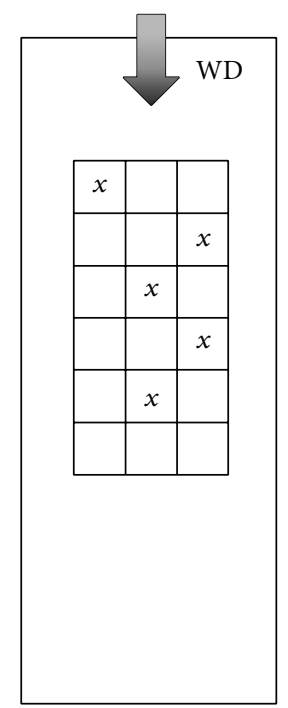

FIGURE 6: Optimal small-scale wind field configuration.

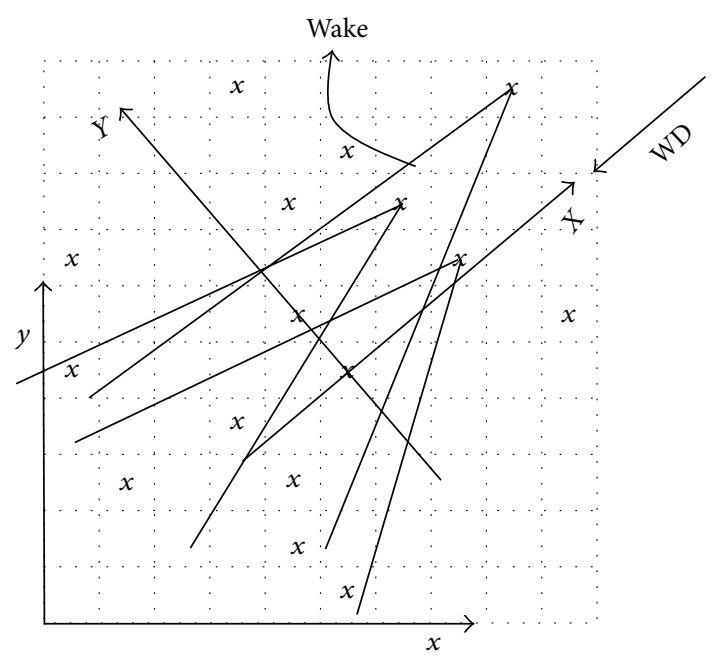

FIGURE 7: Wind field with relative and global coordinate systems, as well as wakes.

(WD vector in Figure 7) and the zero coordinates centred on the actual turbine. Figure 7 shows the wind farm with its global and relative coordinates systems. The same figure shows some turbine wakes.

Using the $X-Y$ coordinate system, a wind turbine may be in the wake of a forward turbine if the latter has a positive $X$ coordinate value. This condition is not sufficient to have actual wind turbine in wake of the forward turbines. The second condition relates to the wake radius at each turbine's location. Mathematically, the wake radii calculated at each $X$ coordinate must be greater than the corresponding $Y$ coordinate as an absolute value. 


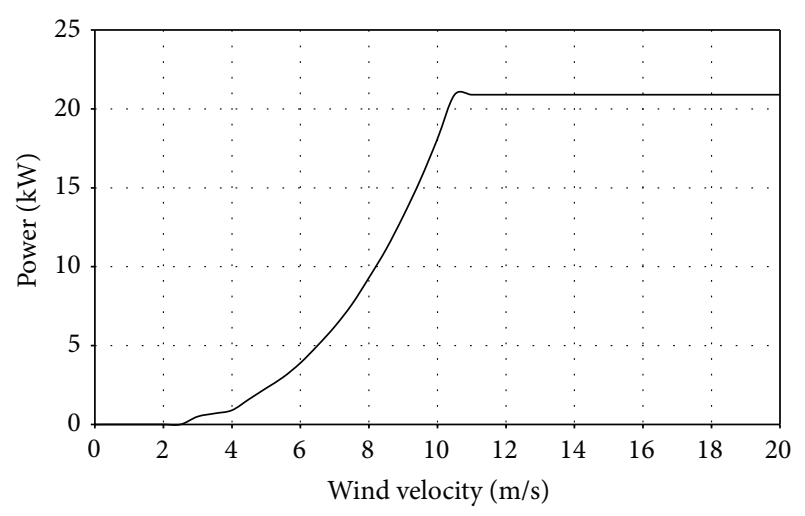

FIGURE 8: Wind turbine characteristic.

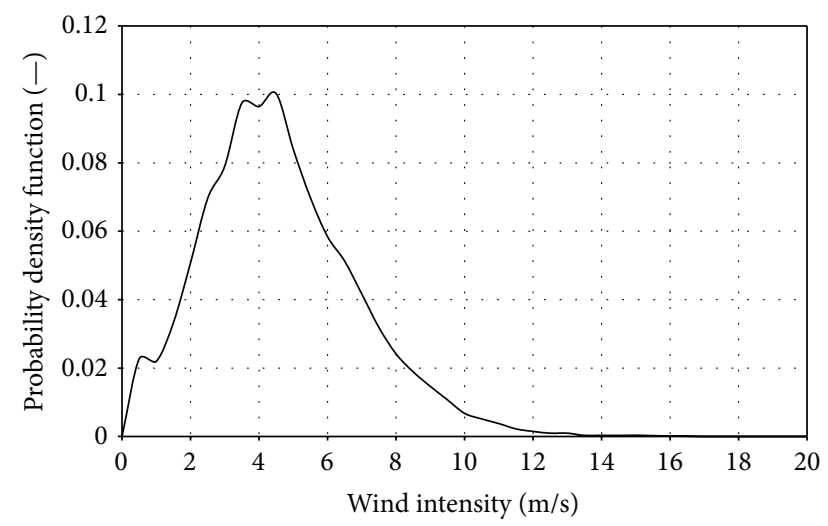

FIGURE 9: Test case site wind probability density function.

Therefore, the two conditions in (6) must be valid for each turbine in forward turbine wakes:

$$
\begin{gathered}
X>0, \\
|Y| \leq r(X),
\end{gathered}
$$

where $r(X)$ is the wake radius calculated at distance $X$ from the turbine for each forward wind turbine.

As far as the Monte Carlo Method simulation is concerned, the method is used to randomly place a certain number of wind turbines on a certain terrain. Several sets of Monte Carlo simulations were carried out to verify if the algorithm is sensitive to the number of attempts. In this work, 10,000 attempts are the best trade-off between accuracy and CPU time.

In this work, a small size wind turbine was used: JIMP20 manufactured by Jonica Impianti. The wind turbine power output versus wind velocity is shown in Figure 8, while Table 1 reports the main turbine characteristics.

Wind direction variation was taken into account in the optimization procedure. Thus, velocity and direction data (measurements every $10 \mathrm{~min}$ ) for a specific site (as an example) were used $[21,22]$. The probability density function (pdf) of the wind intensity and wind direction frequency for
TABLE 1: Main wind turbine characteristics.

\begin{tabular}{lc}
\hline Description & Value \\
\hline Manufacturer & Jonica Impianti \\
Model & JIMP20 \\
Power & $20 \mathrm{~kW}$ \\
Rotor diameter & $8 \mathrm{~m}$ \\
Blade number & 3 \\
Blade air foil & SG6040-6041 \\
Hub height & $15 \mathrm{~m}$ \\
Rotational speed & $100-200 \mathrm{r} / \mathrm{min}$ \\
Cut in wind velocity & $3.5 \mathrm{~m} / \mathrm{s}$ \\
Cut out wind velocity & $37.5 \mathrm{~m} / \mathrm{s}$ \\
Over speed control & Active \\
Yaw control & Passive \\
Generator & Synchronous permanent magnet \\
Electric tension & $380 \mathrm{~V} \mathrm{AC}$ \\
\hline
\end{tabular}

the test case site are shown in Figure 9 and Figure 10, while Figure 11 shows a satellite image with its positioning grid. Figure 10 shows wind direction frequencies. The dominant wind was at $260 \mathrm{deg}$ with an average velocity of $5.44 \mathrm{~m} / \mathrm{s}$ $[21,22]$.

Two different studies were carried out to verify algorithm performance. Firstly, 10,000 Monte Carlo simulations were run taking into account all the wind intensity and wind direction data in one year (case 1). Secondly, another 10,000 Monte Carlo simulations were run taking into account dominant wind direction and intensity only (case 2 ). In both cases, 30 wind turbines were considered.

\section{Results and Discussion}

Research into optimal wind turbine placement highlighted that most authors only considered dominant wind direction and magnitude. This is a restrictive approximation considering how high the wind varies in specific sites. Thus, results obtained by neglecting wind direction and magnitude variability tend to be less precise in annual energy production estimation. Therefore, investors in the wind energy sector would not have had the correct cash flow using that economic analysis. The technique in this paper can estimate annual energy production more precisely.

Figure 12 and Figure 13 show turbine optimal placement after 10,000 Monte Carlo simulation runs for cases 1 and 2. The annual energy obtained directly from the Monte Carlo simulations was $692,360 \mathrm{kWh} /$ year (case 1) and $753,190 \mathrm{kWh} /$ year (case 2).

Figure 12 and Figure 13 show optimal wind turbine placement (Figure 12) using all the wind data (directions and intensities) presenting a slightly scattered distribution, while the placement (Figure 13) using the dominant wind data prevalently aligned with the dominant wind direction. In both cases the entire available terrain surface was taken up. 


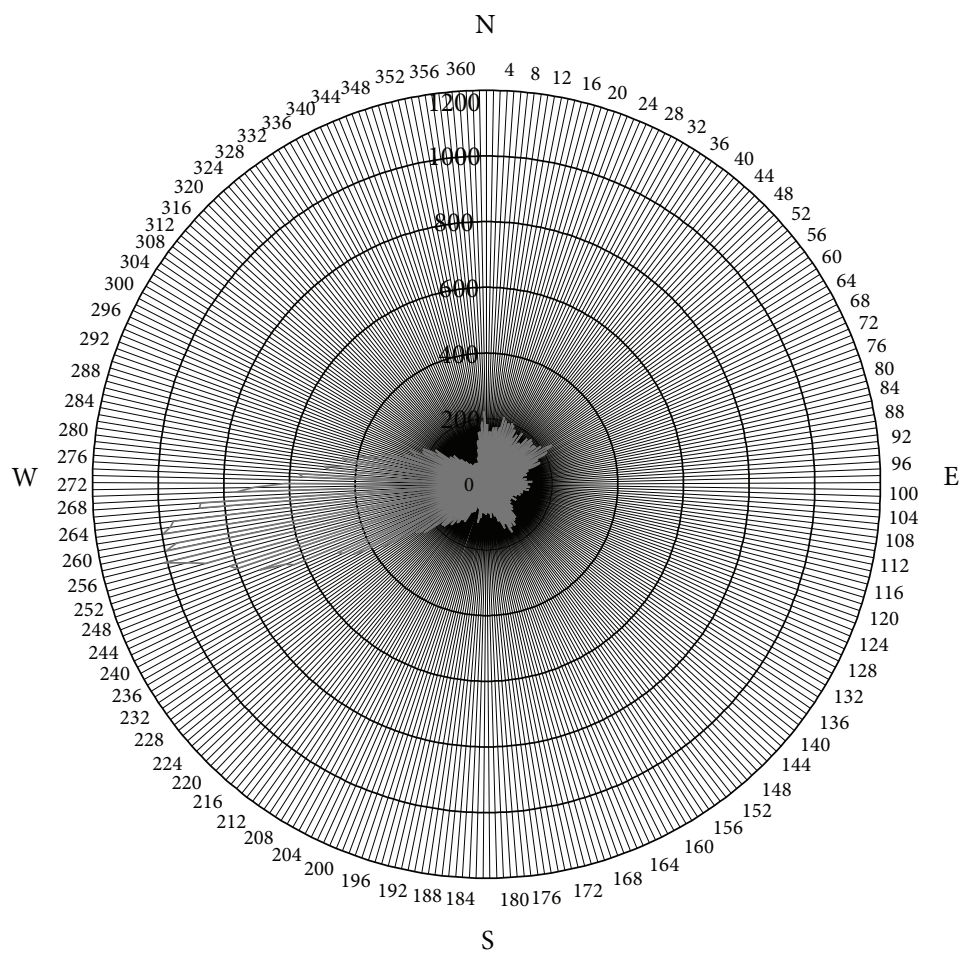

FIgURE 10: Test case site wind direction frequency.

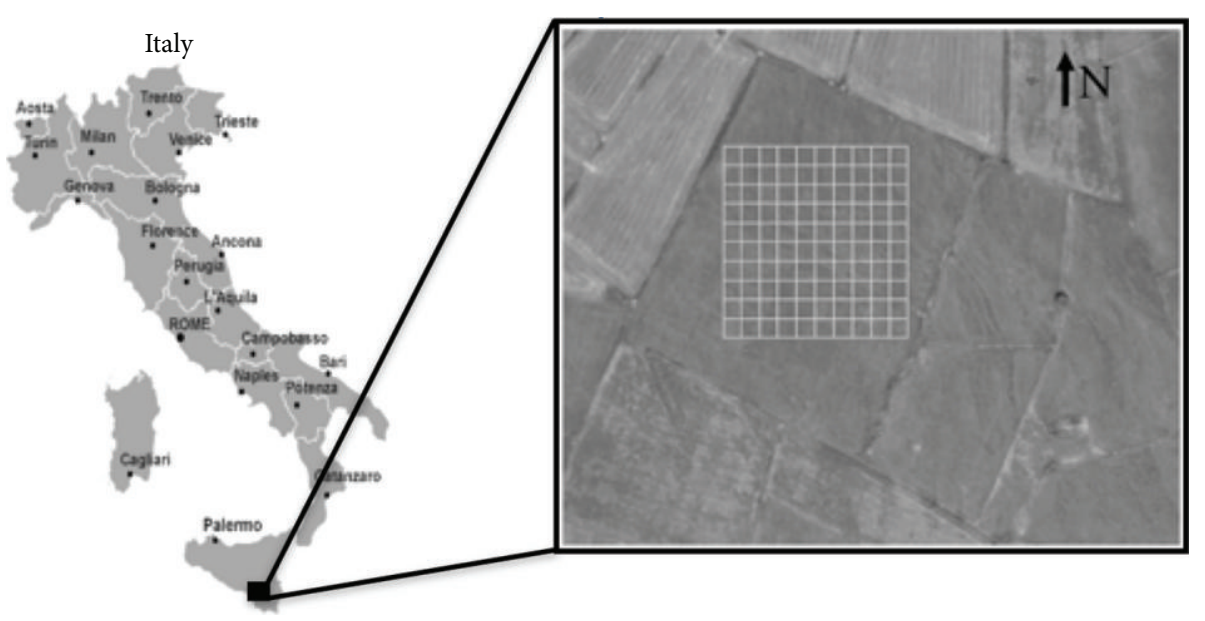

FIGURE 11: Case study site and positioning grid.

The results also show that optimization using the dominant wind direction and intensity tends to overestimate annual energy production by $8.79 \%$ compared to those calculated using all the wind direction and intensity data.

\section{Conclusions}

This study presents a new optimization technique for wind turbine placement based on the Monte Carlo method. The annual energy output of the wind park was used as a fitness parameter, while wind turbine position was considered an independent variable. The mathematical model takes into account wind turbine interaction, as well as wind direction and intensity, as a function of time. By considering wind variability in the optimization method, instead of a fixed wind, a new and more precise way to set up a wind park is revealed. This led to a more realistic estimation of annual energy production.

To verify model accuracy, an experimental test in a wind tunnel was carried out using a small-scale wind field with correspondingly small-scale wind turbines. Moreover, 


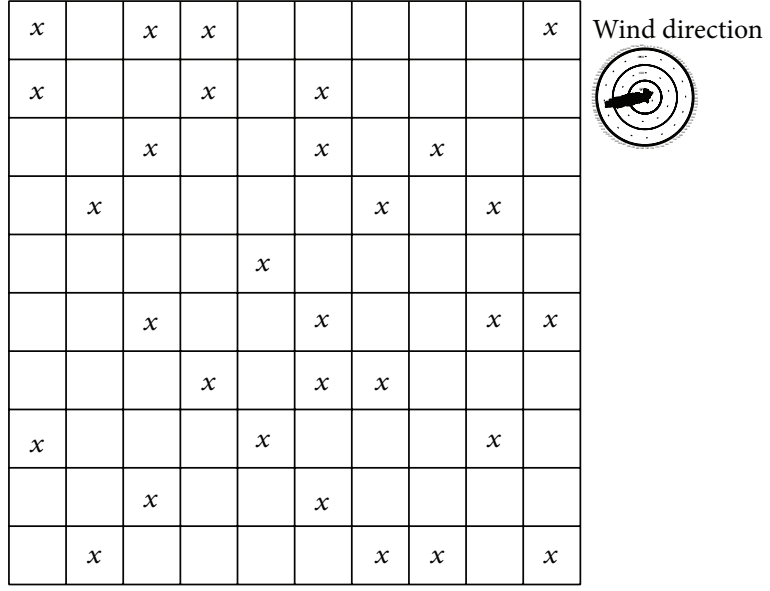

Figure 12: Optimal placement after 10,000 Monte Carlo simulation runs (case 1).

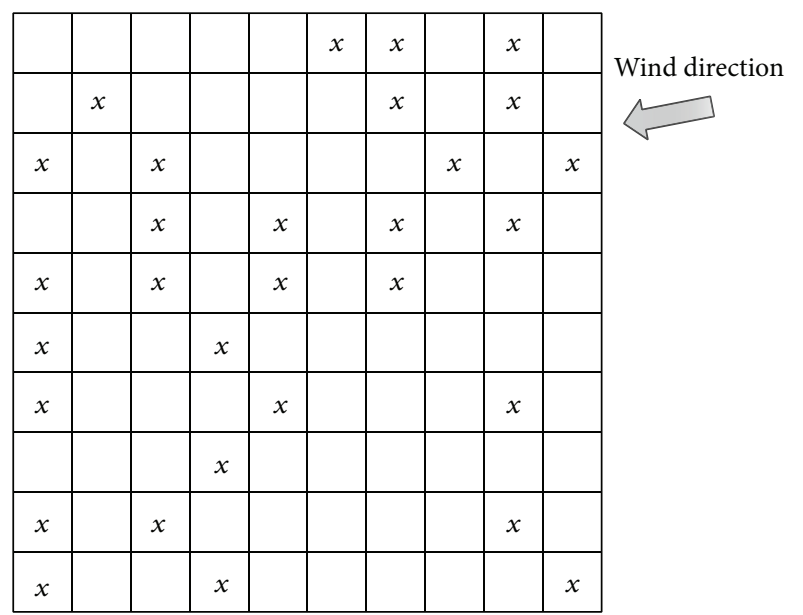

FIGURE 13: Optimal placement after 10,000 Monte Carlo simulation runs (case 2).

a simulation of the experimental model was run using the implemented algorithm. By comparing the experimental and simulated results, it is possible to notice how the model is able to predict wind park power output with a low error (less than $4 \%)$. Thus, the model is capable of taking into account turbine interactions correctly.

In this paper, two main studies were carried out and presented. The first study is based on the use of wind data in terms of direction and intensity per year. In the second, only dominant wind direction and intensity were used.

The results suggest that optimal wind turbine placement should take into account changing wind direction and intensity which can lead to a scattered wind turbine distribution on the ground, while placement using only the dominant wind data prevalently aligned with the dominant wind direction. In both cases, all the available terrain surface is taken up. Moreover, using dominant wind intensity tends to overestimate the annual energy production by about $9 \%$. Thus, using all the wind data leads to a more precise annual energy evaluation and a more optimal placement of wind turbines.

\section{Nomenclature}

$a[-]: \quad$ Axial induction factor

$\alpha[-]: \quad$ Entrainment constant

$N[-]: \quad$ Number of wind turbines in the field

$r_{0}[\mathrm{~m}]: \quad$ Wind turbine rotor radius

$D_{0}[\mathrm{~m}]: \quad$ Wind turbine rotor diameter

$d_{0}[\mathrm{~m}]: \quad$ Small-scale wind turbine rotor diameter

$D_{\mathrm{wt} h}[\mathrm{~m}]$ : Hydraulic diameter of wind tunnel test section

$L_{\mathrm{wt}}[\mathrm{m}]: \quad$ Wind tunnel test section length

$r[\mathrm{~m}]: \quad$ Wake radius at distance $x$

$u_{0}[\mathrm{~m} / \mathrm{s}]$ : Wind velocity of undisturbed wind

$v[\mathrm{~m} / \mathrm{s}]: \quad$ Air velocity at distance $x$ in the wake

$v_{0}[\mathrm{~m} / \mathrm{s}]:$ Air velocity just behind the wind turbine rotor

$v_{N}[\mathrm{~m} / \mathrm{s}]:$ Air velocity downstream of $N$ turbines

$x[\mathrm{~m}]: \quad$ Distance from the rotor

$z_{0}[\mathrm{~m}]: \quad$ Surface roughness of the installation site

$z[\mathrm{~m}]: \quad$ Wind turbine hub height.

\section{Conflict of Interests}

The authors declare that there is no conflict of interests regarding the publication of this paper.

\section{References}

[1] European Parliament, "Climate and energy package," 2008.

[2] European Wind Energy Association (EWEA), "Wind in Power: 2009 European Statistics," 2010.

[3] MathWorks, "Matlab user manual and documentation," 2010.

[4] M. R. Patel, Wind and Power Solar Systems, CRC Press, Boca Raton, Fla, USA, 1999.

[5] R. C. Bansal, T. S. Shatti, and D. P. Kothari, "On some of the design aspects of wind energy conversion systems," Energy Conversion and Management, vol. 43, no. 16, pp. 2175-2187, 2002.

[6] I. Ammara, C. Leclerc, and C. A. Masson, "Viscous threedimensional differential/actuator-disk method for the aerodynamic analysis of wind farms," Journal of Solar Energy Engineering, vol. 124, no. 4, pp. 345-356, 2002.

[7] G. Mosetti, C. Poloni, and B. Diviacco, "Optimization of wind turbine positioning in large windfarms by means of a genetic algorithm," Journal of Wind Engineering and Industrial Aerodynamics, vol. 51, no. 1, pp. 105-116, 1994.

[8] C. T. Kiranoudis, N. G. Voros, and Z. B. Maroulis, "Short-cut design of wind farms," Energy Policy, vol. 29, no. 7, pp. 567-578, 2001.

[9] S. A. Grady, M. Y. Hussaini, and M. M. Abdullah, "Placement of wind turbines using genetic algorithms," Renewable Energy, vol. 30, no. 2, pp. 259-270, 2005.

[10] G. Marmidis, S. Lazarou, and E. Pyrgioti, "Optimal placement of wind turbines in a wind park using Monte Carlo simulation," Renewable Energy, vol. 33, no. 7, pp. 1455-1460, 2008.

[11] N. O. Jensen, A Note of Wind Generator Interaction, Risø National Laboratory, Roskilde, Denmark, 1993. 
[12] P. Vermeulen, P. Builtjes, J. Dekker, and G. L. van Bueren, "An experimental study of the wake behind a full scale vertical-axis wind turbine," TNO-Report No. 79-06118, Laan van Westenenk, Apeldoorn, The Netherlands, 1979.

[13] J. Højstrup, “Nibe Wake, part one," Tech. Rep., Risø National Laboratory, Roskilde, Denmark, 1983.

[14] M. H. Kalos and P. A. Whitlock, Monte Carlo Methods, WileyVCH, 2008.

[15] R. Lanzafame and M. Messina, "Fluid dynamics wind turbine design: critical analysis, optimization and application of BEM theory," Renewable Energy, vol. 32, no. 14, pp. 2291-2305, 2007.

[16] F. James, "Monte Carlo theory and practice," Reports on Progress in Physics, vol. 43, no. 9, pp. 1145-1189, 1980.

[17] J. M. Hammersley and D. C. Handscomb, Monte Carlo Methods, Chapman \& Hall, London, UK, 1979.

[18] S. Brusca, R. Lanzafame, and M. Messina, "Low-speed wind tunnel: design and build," in Wind Tunnels: Aerodynamics, Models and Experiments, J. D. Pereira, Ed., Nova Science, New York, NY, USA, 2011.

[19] J. B. Barlow, W. H. Rae, and A. Pope, Low-Speed Wind Tunnel Testing, John Wiley \& Sons, New York, NY, USA, 1999.

[20] J. R. Turner and J. F. Thayer, Introduction to Analysis of Variance, SAGE Publications, 2001.

[21] R. Daley, Atmospheric Data Analysis, Cambridge University Press, Cambridge, UK, 1996.

[22] R. Gnanadesikan, Methods for Statistical Data Analysis of Multivariate Observations, John Wiley \& Sons, New York, NY, USA, 1997. 

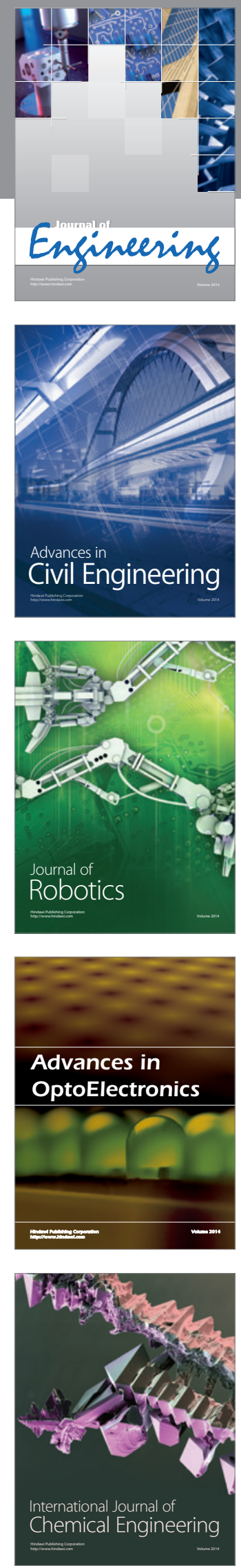

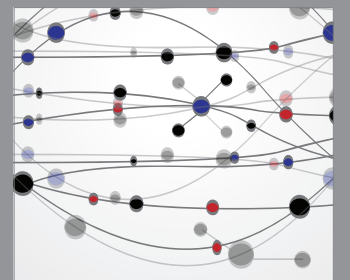

The Scientific World Journal
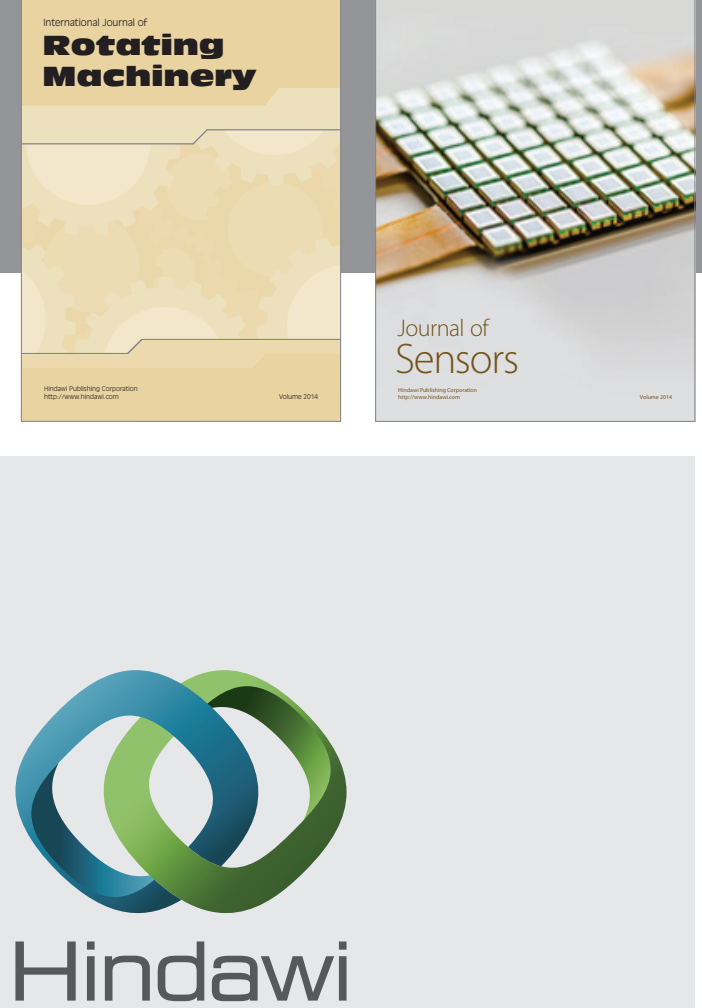

Submit your manuscripts at http://www.hindawi.com
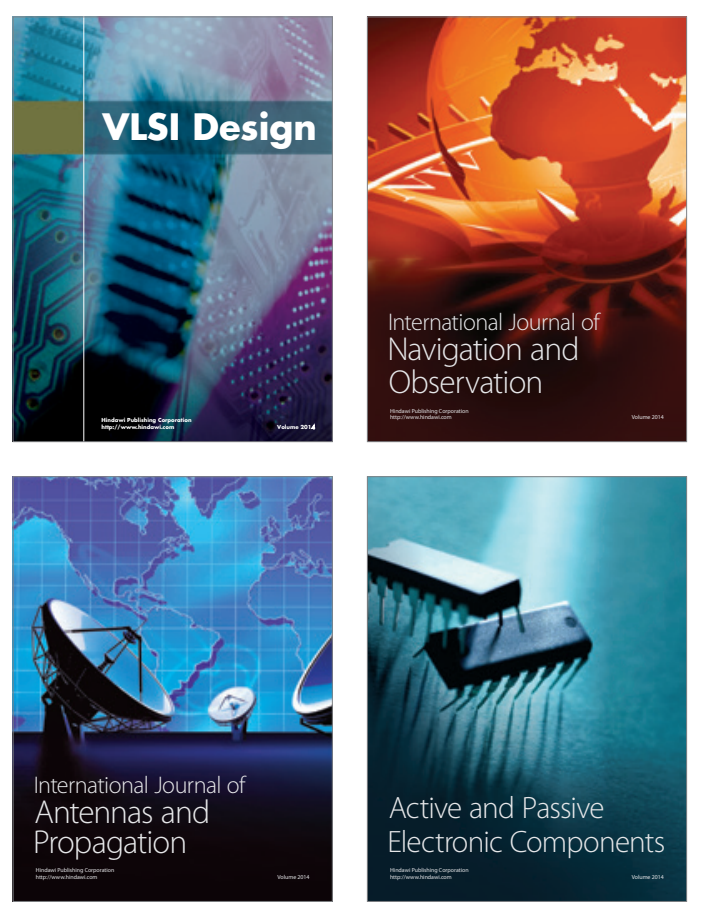
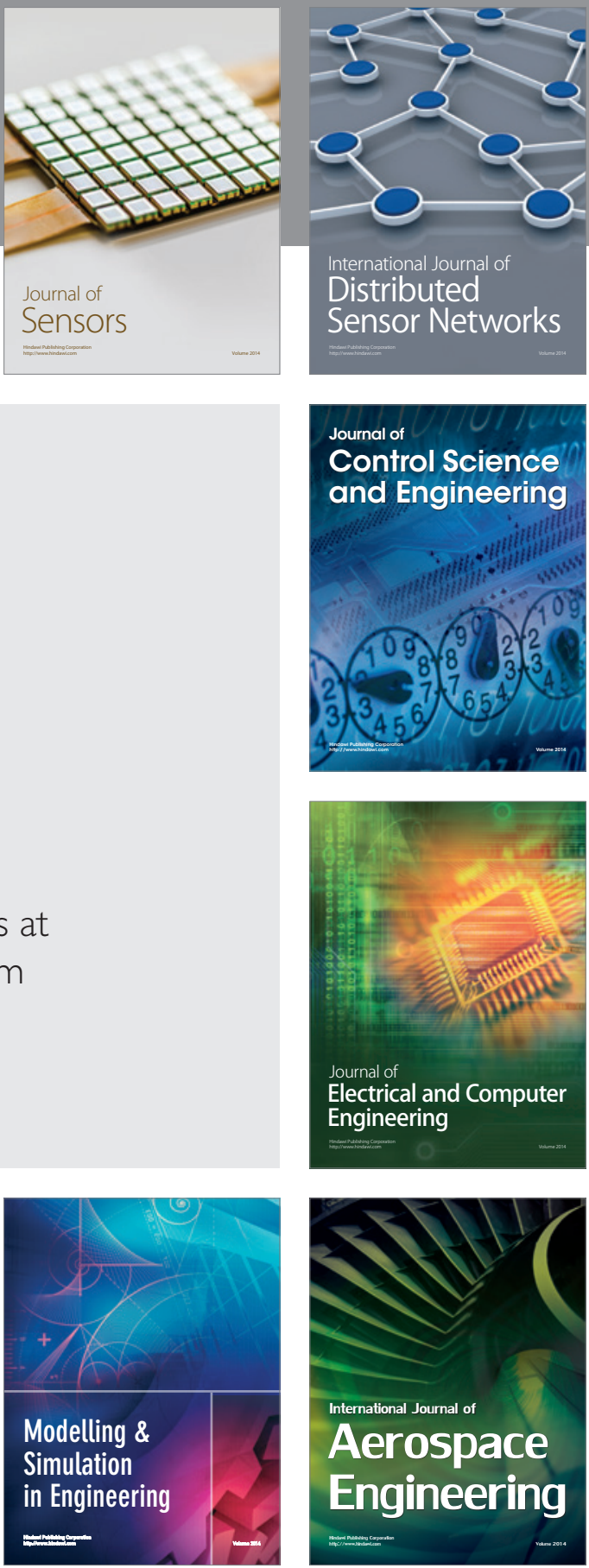

Journal of

Control Science

and Engineering
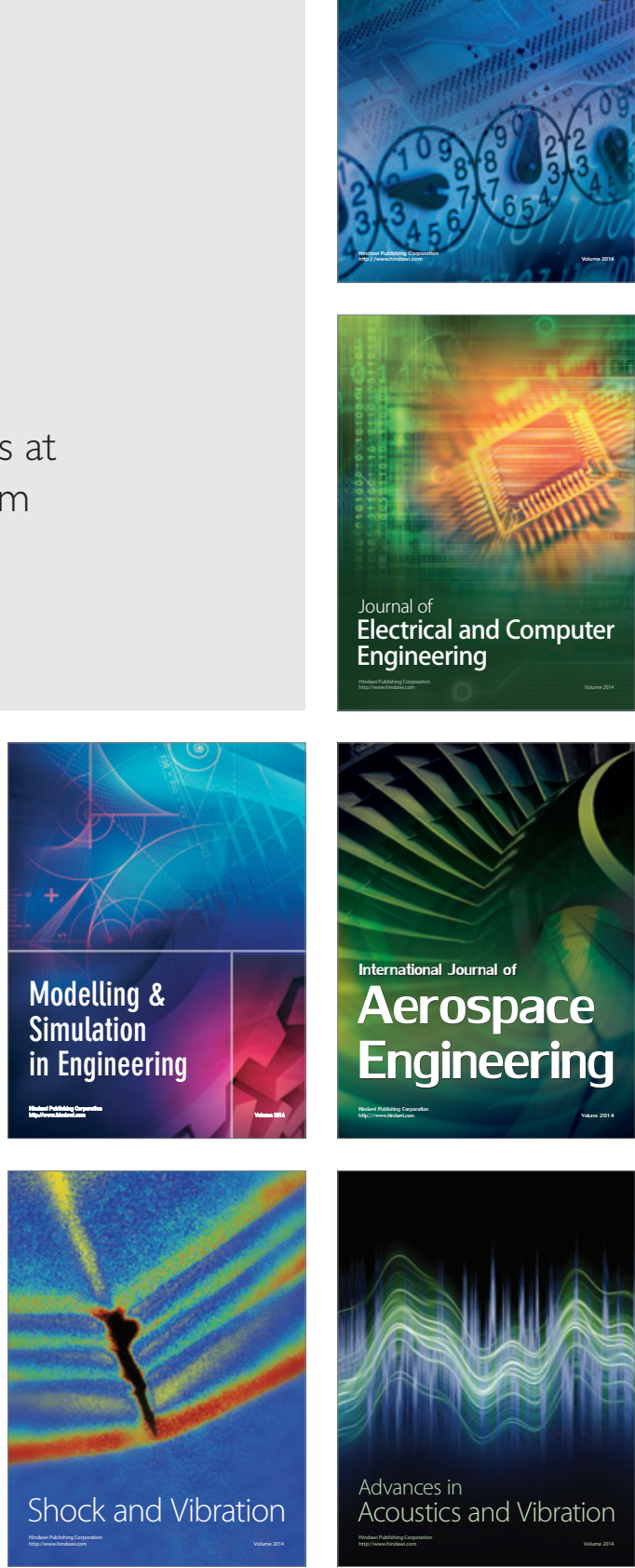